\title{
Assessment of Hostile Attribution Bias in Early Childhood
}

\author{
Marine Houssa*, Nathalie Nader-Grosbois, Alexandra Volckaert \\ Institute of Psychological Sciences, Université Catholique de Louvain, Louvain-la-Neuve, Belgium \\ Email: *marine.houssa@uclouvain.be,nathalie.nader@uclouvain.be, alexandra.volckaert@uclouvain.be
}

How to cite this paper: Houssa, M., Nader-Grosbois, N., \& Volckaert, A. (2018). Assessment of Hostile Attribution Bias in Early Childhood. Psychology, 9, 958-976. https://doi.org/10.4236/psych.2018.95060

Received: January 29, 2018

Accepted: May 8, 2018

Published: May 11, 2018

Copyright ( 2018 by authors and Scientific Research Publishing Inc. This work is licensed under the Creative Commons Attribution International License (CC BY 4.0).

http://creativecommons.org/licenses/by/4.0/

\section{cc) (i) Open Access}

\begin{abstract}
In the literature, the tendency to attribute hostile intent is called "hostile attribution bias". After ambiguous provocation, aggressive children are more likely than nonaggressive children to attribute a hostile intent to the peer. Children who make hostile attribution bias are generally more rejected by peers. However, it seems that nonaggressive children may also attribute hostile intentions to peers. The goals of these studies are 1) to detect the profile of young children who attribute hostile intentions and 2) to identify if there is difference between children who showed hostile attribution bias and those who did not. In the first study, 176 preschoolers were tested with the Unfair Card Game, that is a virtual game inducing frustration/provocation and including a high level of personal involvement. In the second study, 102 children were also tested with the Unfair Card Game, but also with some measures of social cognition. In both studies, parents and teachers completed some questionnaires. Results showed notably that children who displayed HAB manifested less positive affects and more negative affects during the frustration task. Compared with children who displayed no hostile attribution bias, children who did do so were perceived by teachers as more extraverted and by parents as having a higher level of externalizing behavior. It seems possible to identify children who made hostile attribution bias. Results are discussed in relation to the literature on the hostile attribution bias.
\end{abstract}

\section{Keywords}

Hostile Attribution Bias, Preschoolers, Assessment

\section{Introduction}

Over the past few decades, numerous studies have reported that aggressive children differ from nonaggressive children in their social information 
processing (SIP) (see Orobio de Castro, Veerman, Koops, Bosch, \& Monshouwer, 2002 for a meta-analysis). Following on from this, researchers studied the link between individual differences in children's aggressive behavior and in their attributional responses (e.g., Pettit, Dodge, \& Brown, 1988; Runions \& Keating, 2007). After ambiguous provocation, aggressive children were found to be more likely than nonaggressive children to attribute a hostile intent to the peer (Dodge \& Frame, 1982). However, it seems that nonaggressive children may also attribute hostile intentions to peers (Choe, Lane, Grabell, \& Olson, 2013). In the literature, the tendency to attribute hostile intent to peers is also called "hostile attribution bias" (HAB). According to Orobio de Castro et al. (2002), HAB could be a key element in the development-and persistence-of behavior problems in time. It could be useful for the early identification of children at risk of developing behavior problems later. However, there are few effective tools for detecting HAB. More particularly, it would be useful to detect the profile of young children who attribute hostile intentions, as well as the profile of young children in whom the development of $\mathrm{HAB}$ is impeded.

Most recent studies of HAB are based on the reformulated SIP model of Crick and Dodge (1994). According to this model, there are six steps in reacting appropriately to social situations. First, the social cues have to be encoded 1) before being interpreted 2). Then, a goal has to be selected 3), and alternative responses have to be generated 4). After that, the alternative responses are evaluated to select the best one 5). Finally, the selected response has to be enacted 6). HAB corresponds to an incorrect use of the SIP, and more precisely of step 2 (interpretation of social cues).

Which children exhibit $\mathrm{HAB}$ ?

Aggressive children exhibit more $\mathrm{HAB}$ than nonaggressive children (see Orobio de Castro et al., 2002 for a meta-analysis). However, some authors have reported other factors which could lead to HAB. For example, Pettit et al. (1988) observed that children with low socio-economic status nearly always displayed $\mathrm{HAB}$; they suggested that these children were unable to understand the question or the intention notion, and then inferred hostile motives from the negative outcome of the situation. Furthermore, in their meta-analysis, Orobio de Castro et al. (2002) studied the relation between HAB and aggressive behaviors by assessing the impact of several children's characteristics on this relation like the degree and type of behavior problems, sociometric status or intelligence. First, the level of externalizing behavior (EB) problems was found to have an impact on the effect size of the relation between HAB and aggressive behaviors. This effect was bigger when children had EB problems combined with a low sociometric status. Second, the authors found that after controlling for intelligence, the effect size was less important.

More recently, Choe et al. (2013) argued that the relation between social cognition and EB may exist partially because deficits in interpreting others' mental states-in other words, limitations in Theory of Mind (ToM) - could lead to 
$\mathrm{HAB}$. In an ambiguous situation, if a child is not able to distinguish between what he feels and what others feel, he or she could for example conclude that because he or she feels bad, the peer's intention is bad too. To examine the influence of social cognitive competences, we included a measure of SIP and measures of ToM in our studies.

As mentioned above, intelligence or general cognitive functioning is linked with HAB (Orobio de Castro et al., 2002; Runions \& Keating, 2007). Furthermore, both language skills and IQ are highly correlated with social cognition (Astington \& Baird, 2005; Carlson \& Moses, 2001). To control for the effect of verbal and non-verbal cognitive functioning on $\mathrm{HAB}$ in preschoolers, we assessed verbal and non-verbal developmental quotient using standard measures.

Impacts of $\mathrm{HAB}$

Children with a distortion of the SIP (in particular step 2-interpretation of social cues) generally have a higher level of EB or aggressive behaviors. Orobio de Castro et al. (2002) also argued that HAB contributes to rejection by peers (and vice versa) and limits opportunities to learn prosocial behaviors. In other words, SIP skills and HAB tendencies are linked with children's social adjustment (e.g., Crick \& Dodge, 1994). Moreover, as reported by Crick and Dodge (1994), maladjusted children are more likely to make external attributions even when this has positive social outcomes. Making hostile attributions can inhibit the capacity to develop positive social efficacy, even if those children experience social success. In view of these results, we included a measure of social adjustment in the present studies.

How should HAB be detected?

Recently, several authors have developed measures to evaluate HAB by young children. For example, Schultz et al. (2010) developed the Schultz Test of Emotion Processing-Preliminary Version (STEP-P). This tool contains 62 short videos of children enacting social situations. Through open-ended questions such as "Why do you think the [provoker] [provoked the child]?" with reference to the specific characters and actions in each video, the experimenter can evaluate $\mathrm{HAB}$. If the child has not provided enough information, closed-ended questions are asked, such as "Is the [provoker] angry at the [protagonist]?" or "Was the [provoker] being mean?". Secondly, Van Nieuwenhuijzen, Vriens, Scheepmaker, Smit, and Porton (2011) assessed SIP through hypothetical situations presented in cartoons, cards and video vignettes. HAB is assessed by asking “X happened. Did it happen on purpose or accidentally?". Thirdly, Ziv and Sorongon (2011) developed the Social Information Processing Interview for Preschoolers (SIPI-P). This tool contains four stories about bears presented in a picture book. To evaluate $\mathrm{HAB}$, this tool includes closed-ended questions such as "Do you think the other child who did not let [the protagonist] play is mean or not mean?" or "What would you say or do if this happened to you?", with three possible answers being suggested (corresponding to an aggressive, inept or competent reaction). More recently, Choe et al. (2013) told children to imagine a 
situation (i.e., a friend spilled his glass all over you) and then asked questions such as "What do you think happened?" and "Did [the provoker] do that by accident or on purpose?".

In summary, $\mathrm{HAB}$ in young children can be evaluated in different ways, including videos or stories illustrating critical social situations (peer provocation, physical transgression, peer rejection, etc.). Typically, SIP assessments instruct participants to imagine they are the protagonist in the vignette and ask short open and closed-ended questions to evaluate HAB. If children report the provoker as being angry or "mean", this can be considered as a hostile intent attribution (Schultz et al., 2010).

Moreover, Dodge and Frame (1982) showed that HAB can only happen when children feel involved in the social situation presented. In the same way, Orobio de Castro et al. (2002) predicted a stronger effect size of the relation between $\mathrm{HAB}$ and aggressive behaviors when personal involvement in the social situation was high. This personal involvement would be highest if the child really took part in the interaction him- or herself.

The results of previous studies suggest that it would be useful to be able to identify young children who are likely to display HAB in order to intervene and teach them to interpret social cues correctly in ambiguous social situations (step 2 of the SIP model), thereby fostering their social adjustment and impeding peer rejection. Furthermore, it is known that HAB is more present when children imagine that the provocation is directed towards them and not towards another peer, but also when the personal involvement is high (Dodge \& Frame, 1982; Orobio de Castro et al., 2002). In these studies, we decided to use the same type of open and closed-ended questions as cited above, but in an ambiguous/frustration task directly involving the child in order to increase personal involvement.

\section{Study 1}

\subsection{Objectives}

The goal of this study was to know if it is possible to detect the emergence of $\mathrm{HAB}$ versus prosocial attribution by preschoolers when they experience a situation of frustration/provocation (for example, when they feel threatened by a peer or frustrated by an unjustly lost game) or an ambiguous situation (when a behavior could have been either accidental or intentional). In other words, is it possible to identify at risk children thanks to a measure of SIP with a high level of personal involvement? We tried to answer this question using a qualitative analysis of reply patterns.

\subsection{Method}

\section{Participants}

One hundred and seventy-six children ( 76 boys and 100 girls) between 2 years 11 months and 6 years 2 months $(M=4.7$ years, $\mathrm{SD}=.74)$ took part in this 
study. The level of education of the parents was indicated on a six-point scale from low (elementary school not completed) to high (university) with a mean of 5.02 (SD = .99); 5 corresponded to "short higher education". The family income was indicated on a four-point scale from low (less than $€ 1000)$ to high ( $€ 4000$ or more), and the mean was $2.91(\mathrm{SD}=.73) ; 3$ corresponded to $€ 2500-4000$ a month.

Participants were recruited in Belgian French-speaking schools. Their teachers identified children who met the inclusion criterion (have an elementary level of comprehension and production of spoken French). The teachers and parents were encouraged to take part in the study. Information letters and a consent form for the child's participation were sent to these parents. Children were excluded if they displayed developmental delay or intellectual disabilities.

Procedure

Two different tests were initially administered to each participant. The tests were a measure of $\mathrm{HAB}$ and a measure of developmental quotient. Total administration time was 25 minutes. Children were tested individually in a quiet room. All participants were tested at school or at the Institute of Research in Psychological Sciences. Parents completed the CBCL (Achenbach \& Rescorla, 2000) and teachers completed the EBMCF (Roskam, De Maere-Gaudissart, \& Vandenplas-Holper, 2000).

\section{Instruments}

Individual characteristics

To exclude children with developmental disabilities, we administered the WPPSI (Weschler, 2004) or the EDEI-R (Perron-Borelli, 1996) (data were collected as part of several studies) to each child. These measures made it possible to control for developmental quotient.

Wechsler Intelligence Scales-third edition (Weschler, 2004).

An overall score of around 10 on these scales was a criterion for children's inclusion in the sample. They distinguish between the verbal and the non-verbal intellectual quotient (IQ). Testing verbal IQ provided assurance that children had a level of language sufficient to understand instructions during testing and training sessions. In the present study, the verbal IQ was obtained from the "information" scale, while the performance IQ was obtained from the "block design" scale. In terms of validation, the intercorrelations calculated between raw scores on all scales were high. We included children with a global score between 5.5 and 14.5 (1.5 SD). This global score was the mean of the two subscales.

Differential Scales of Intellectual Efficiency-Revised edition (EDEI-R, Perron-Borelli, 1996).

These validated scales were used in the pretest session to check that children had a global developmental age between 3 years and 6 years 6 months, as a criterion for inclusion in the sample. Those scales allow a distinction to be made between the verbal developmental age and the non-verbal developmental age. The verbal developmental age was obtained by means of scores on two scales: "knowledge" and "social understanding." The non-verbal developmental age was 
obtained by means of "practical adaptation." As regards validation, the intercorrelations calculated between the raw scores on all scales were high: they varied between .47 and .88 ; half of the scores were .70 or below.

Bipolar Rating Scales based on the Five Factor Model (EBMCF, Roskam et al., 2000).

This questionnaire measures the child's personality with reference to five factors (extraversion, agreeableness, conscientiousness, emotional stability, and openness). The 25 items are completed by caregivers (or teachers), by choosing between two opposite adjectives on a Likert scale. The validation was carried out with 321 typically developing children. The factor analysis revealed the five expected factors, for which the Cronbach's alphas were between .70 and .93. The coefficients of test-retest stability were highly significant and varied between .66 and .93 for teachers and between .80 and .89 for caregivers.

Behavior Checklist (CBCL, Achenbach \& Rescorla, 2000).

The CBCL includes items to assess behavioral and emotional problems in children. This measure generates two factors: externalizing and internalizing behaviors. In this study, we focused on the externalizing behavior score (EB), corresponding to the sum of the score on the "Aggressive behavior" subscale (19 items) and on the "Attention problems" subscale (5 items). We were also interested in the "Emotionally reactive" (ER) subscale, which is an internalizing behavior. Caregivers were asked to report, on a Likert scale, if the behavior was never observed, sometimes observed, or often/always observed. The higher the score, the higher the level of EB or ER. The scales from this questionnaire had Cronbach's alpha between .63 and .86 and the test-retest reliability was .85 .

Frustration task and questions assessing $\mathrm{HAB}$

The Unfair Card Game (Roskam et al., 2016).

Based on the Snap game (Hughes et al., 2002), the Unfair Card Game (UCG) is a computerized version of a moving card game which the child plays with a virtual partner (a child of the same age range). It has been designed to elicit spontaneous agitation, negative and positive affect and inattention in the context of play interaction with a virtual peer ("Sam").

In this game, the child's success depends on the partner's performance. Each time the child points to the correct card, a real candy is reserved to the virtual partner and, similarly, each time the virtual partner points to the correct card, a real candy is given to the child. The child starts by playing five rounds of the moving card game, and then the virtual partner plays five more rounds. The trick is that the child is always correct, thus allowing the virtual partner to win five candies (winning phase), whereas the virtual partner loses four rounds and allows the child to receive only one candy (losing phase). To strike a balance, the virtual partner apologizes at the end of the game and gives half of his candy to the child, to reduce the feeling of frustration.

The UCG can be played in contexts such as at home, at school or in a lab session. It lasts approximately 10 minutes. The game situation was supervised by an 
experimenter and filmed so that the child's behavior can be coded on the basis of standardized guidelines in a manual. The grid takes four scales into account: positive affect, negative affect, agitation and inattention. The UCG provides four ordinal scores ranging from 1 to 5 which result from the four scales during the first phase of the game (winning phase). In addition, the UGC provides 16 ordinal scores ranging from 1 to 5 which result from the four scales during each round of the second, losing phase of the game. For each scale, the higher the score, the more the child presented intense and frequent behavior (i.e., positive or negative affects, agitation and inattention).

Validation was conducted with 268 young children, and was based on factorial analysis, reliability analyses, normality tests, inter-rater agreements and external validation.

Questions assessing $\mathrm{HAB}$ versus "prosocial” attribution/response.

We chose the UCG as the provocation situation because some researchers (Dodge \& Coie, 1987; Orobio de Castro et al., 2002) have argued that HAB scores are highest when the child is personally involved. After the UCG, the child was asked some closed-ended and open-ended questions about HAB. As Table 1 shows, the questions were designed with reference to the SIP steps (Crick \& Dodge, 1994) and to SIPI-P (Ziv \& Sorongon, 2011).

The questions were used to assess prosocial attribution versus HAB. For each question, there were several suggested answers, with visual illustrations. For example, for the question about what emotion he/she experienced, the child could choose between four emotions illustrated by four teddy bears. As Table 1 shows, HAB corresponded to answers such as "He made mistakes on purpose to get more candies than me" or "(If I play again,) I will lose on the purpose to stop Sam getting candies". Furthermore, like Schultz et al. (2010) with the STEP-P, we categorized "(He played like that because) he was angry with me" as indicative of HAB too.

\subsection{Results}

Descriptive analysis

Table 2 presents individual and familial characteristics for all subjects. Table 3 presents the distribution of replies in terms of percentages for each question and an interpretation of each answer. Children reported that they felt sadness after the UCG more frequently than any other emotion. Concerning intensity of emotion, more than half replied that they felt this emotion "a lot". Approximately a third of the children exhibited HAB. However, most of the children said that they thought the protagonist lost because the game was too difficult for him, and almost 9 out of 10 children said they would agree to play again. After the positive response, almost $70 \%$ told that they will correctly, whereas $17 \%$ talked about revenge (losing deliberately).

$\mathrm{HAB}$ versus prosocial attribution

Table 4 shows among other things the distribution of responses for Question 1 ("How do you feel?"). As in Table 3, one third of the children replied that they 
Table 1. SIP questions and possible answers.

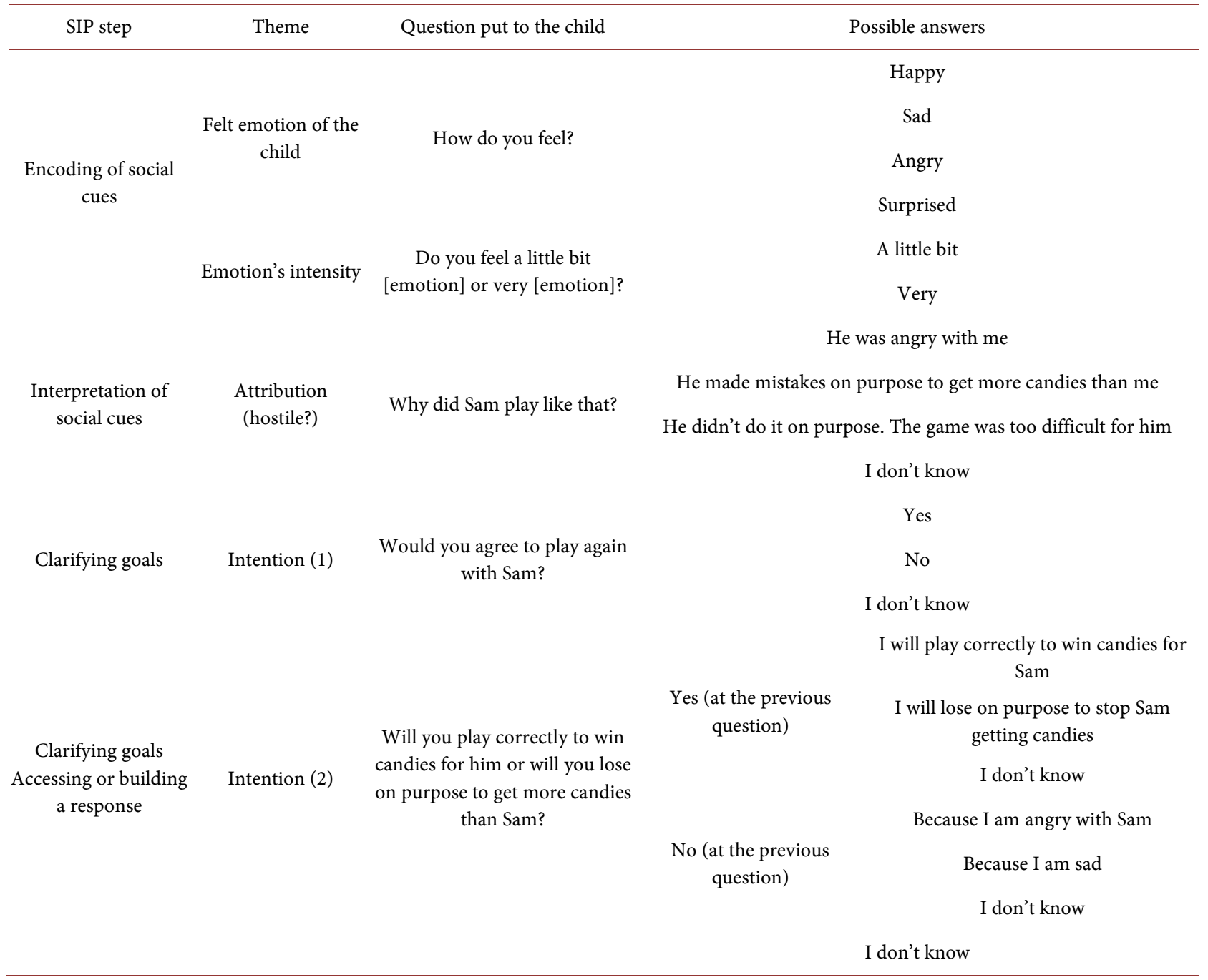

Table 2. Mean scores (standard deviations) of individual and familial variables for study 1 .

\begin{tabular}{|c|c|c|c|c|}
\hline & Variables & & $M$ & $S D$ \\
\hline & Gender (\% Female) & & $56.8 \%$ & \\
\hline & $\mathrm{CA}$ & & 55.44 & 7.39 \\
\hline & DQ & Global & 99.47 & 16.32 \\
\hline & & Verbal & 98.43 & 20.87 \\
\hline & & Non-verbal & 99.46 & 22.64 \\
\hline \multirow[t]{6}{*}{ Individual characteristics } & & Conscientiousness & 6.13 & 1.85 \\
\hline & & Openness & 7.06 & 1.52 \\
\hline & EBMCF & Agreeableness & 6.55 & 1.38 \\
\hline & & Emotional stability & 5.81 & 1.38 \\
\hline & & Extraversion & 6.07 & 1.78 \\
\hline & CBCL & EB Parents & 17.47 & 10.84 \\
\hline
\end{tabular}




\section{Continued}

\begin{tabular}{|c|c|c|c|c|}
\hline \multirow{2}{*}{ Familial characteristics } & & $\begin{array}{l}\text { Higher educational level of } \\
\text { parents }\end{array}$ & 5.02 & .99 \\
\hline & & Incomes & 2.91 & .73 \\
\hline \multirow{4}{*}{ Behavior } & \multirow{4}{*}{ UCG } & Positive affects & 1.40 & .47 \\
\hline & & Negative affects & 1.51 & .50 \\
\hline & & Agitation & 2.42 & .96 \\
\hline & & Inattention & 2.06 & .76 \\
\hline
\end{tabular}

Notes. CA = Chronological Age; DQ = Developmental Quotient. Educational level of parents: 1 = elementary school not completed; $2=$ elementary school; 3 = secondary school; 4 = apprenticeship; $5=$ short higher education; 6 = university. Incomes: $1=$ less than $€ 1000 ; 2=€ 1000-2500 ; 3=€ 2500-4000 ; 4=$ $€ 4000$ or more; EBMCF = Bipolar Rating Scales based on the Five Factor Model; CBCL = Child Behavior Checklist; EB = Externalizing Behavior.

Table 3. Descriptive analysis of the SIP questions for study 1.

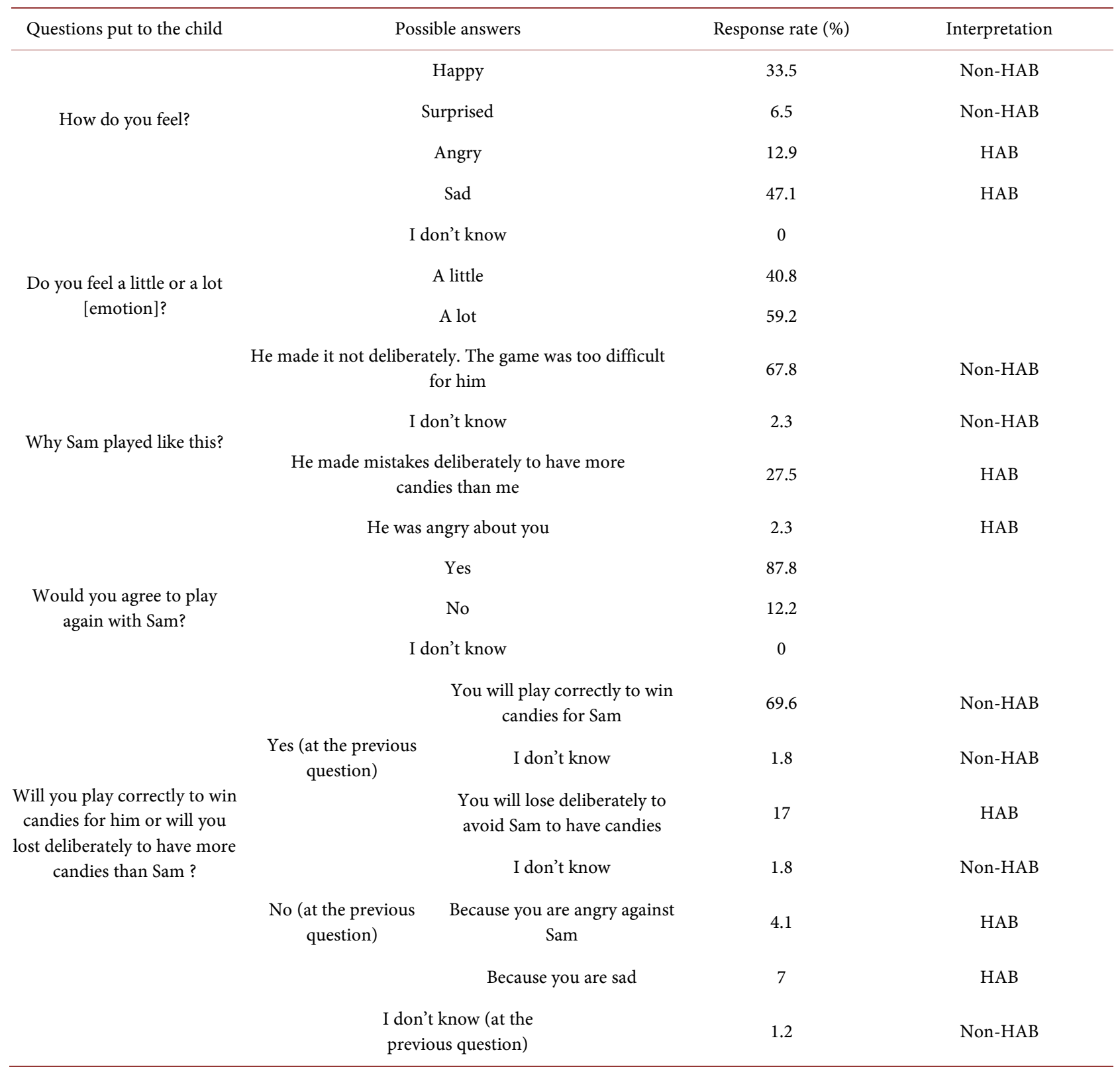


Table 4. Distribution of HAB responses for each question according to the selected emotion.

\begin{tabular}{|c|c|c|c|c|}
\hline $\begin{array}{c}\text { Question } 1 \\
\text { How do you feel? }\end{array}$ & \multicolumn{2}{|c|}{$\begin{array}{c}\text { Question 2 } \\
\text { Why Sam played like this? }\end{array}$} & \multicolumn{2}{|c|}{$\begin{array}{l}\text { Question } 3 \\
\text { Will you play correctly to win candies for him or will you } \\
\text { lost deliberately to have more candies than Sam? }\end{array}$} \\
\hline \multirow{2}{*}{$\begin{array}{l}\text { Happy }(33.5 \%) \\
\text { (non-HAB) }\end{array}$} & HAB & $(22.7 \%)$ & HAB & $(21.4 \%)$ \\
\hline & Non HAB & $(77.2 \%)$ & Non HAB & $(78.6 \%)$ \\
\hline \multirow{2}{*}{ Surprised (6.5\%) (non-HAB) } & HAB & $(9 \%)$ & HAB & $(18.2 \%)$ \\
\hline & Non HAB & $(91 \%)$ & Non HAB & $(72.7 \%)$ \\
\hline \multirow{2}{*}{ Angry (12.9\%) (HAB) } & HAB & $(47.6 \%)$ & $\mathrm{HAB}$ & $(18.1 \%)$ \\
\hline & Non HAB & $(52.4 \%)$ & Non $\mathrm{HAB}$ & $(81.9 \%)$ \\
\hline \multirow{2}{*}{$\begin{array}{l}\text { Sad }(47.1 \%) \\
\quad(\mathrm{HAB})\end{array}$} & HAB & $(33.5 \%)$ & HAB & $(18.2 \%)$ \\
\hline & Non HAB & $(66.5 \%)$ & Non $\mathrm{HAB}$ & $(81.8 \%)$ \\
\hline
\end{tabular}

Notes. $\mathrm{HAB}=$ Hostile Attribution Bias.

felt happy, but nearly half of the sample said they felt sad. $60 \%$ of the children chose sadness or angriness (which could be interpreted as indicative of HAB). For each emotion, is the table then specifies what percentage gave/did not give $\mathrm{HAB}$-indicative responses for Questions 2 and 3. For Question 2, HAB responses were "He was angry with me" or "He made mistakes on purpose to get more candies than me", while non-HAB responses included "He didn't do it on purpose. The game was too difficult for him" or "I don't know". For Question 3, $\mathrm{HAB}$ responses included "I will lose on purpose to stop Sam getting candies" and "Because I am angry with Sam", whereas non-HAB responses were "I will play correctly to win candies for Sam" or "Because I am sad" or "I don't know". Based on the three questions included in Table 4, Figure 1 shows the distribution of reply patterns relative to HAB. As can be seen, a quarter of children never made a hostile attribution, while $30 \%$ made such an attribution in two to three responses.

\section{Study 2}

\subsection{Objectives}

Based on previous research on HAB (e.g., Choe et al., 2013; Orobio de Castro et al., 2002), the objective of this second study was to identify if there was difference between children who showed $\mathrm{HAB}$ and those who did not, after controlling for age, gender and developmental quotient (DQ). More precisely, were there individual differences according to personality factors, social cognition and social adjustment, or level of EB, positive or negative affects, agitation or inattention? Are there specific factors that could increase the risk of attributing a hostile intention and factors that protect against the development of $\mathrm{HAB}$ ? 


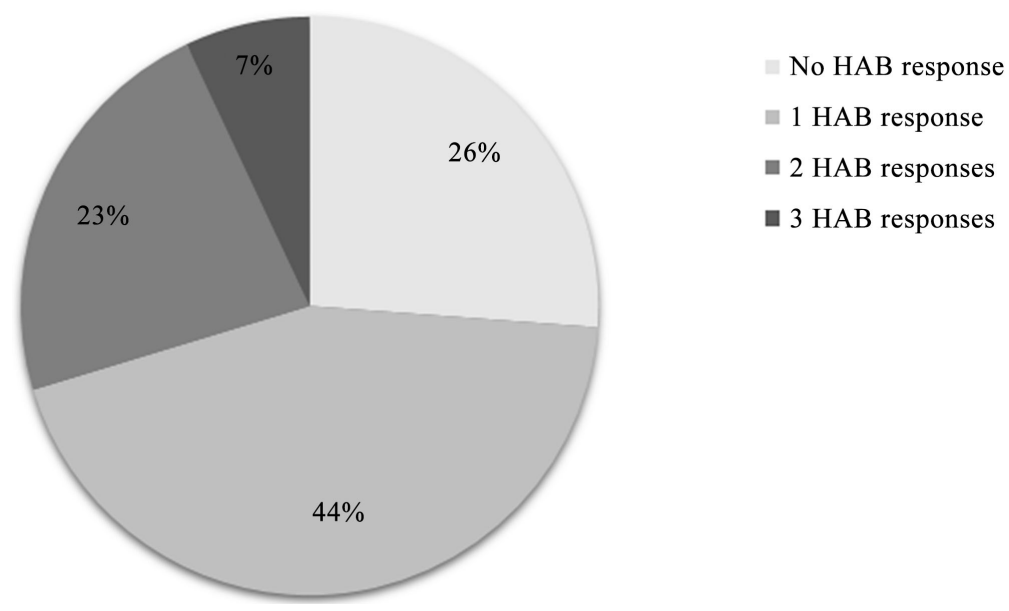

Figure 1. Distribution of HAB profile.

\subsection{Method}

\section{Participants}

The participants were part of the sample of Study 1. One hundred and two children ( 44 boys and 58 girls) aged between 2 years 11 months and 6 years and 2 months $(M=4.7$ years, $\mathrm{SD}=.74)$ were matched on gender, chronological age, DQ (global, verbal and non-verbal) and on their attribution response (at least 2 $\mathrm{HAB}$ responses or less than $2 \mathrm{HAB}$ responses-see Figure 1). The level of education of the parents was indicated on a six-point scale from low (elementary school not completed) to high (university), with a mean of "short higher education" ( $M=5.02, \mathrm{SD}=.99)$. The family income was indicated on a four-point scale from low (less than $€ 1000)$ to high ( $€ 4000$ or more). For this sample, the family income was between $€ 1000-2500$ and $€ 2500-4000$ a month $(M=2.91$, $\mathrm{SD}=.73)$.

\section{Instruments}

Individual characteristics

Wechsler Intelligence Scales-third edition (Weschler, 2004), as described in Study 1.

Differential Scales of Intellectual Efficiency-revised edition (EDEI-R, Perron-Borelli, 1996), as described in Study 1.

Bipolar Rating Scales based on the Five Factor Model (EBMCF, Roskam et al., 2000), as described in Study 1.

Behavior Checklist (CBCL, Achenbach \& Rescorla, 2000), as described in Study 1.

Frustration task and questions assessing the $\mathrm{HAB}$

The Unfair Card Game (Roskam et al., 2016), as described in Study 1.

Questions assessing HAB versus "prosocial" attribution/response, as described in Study 1.

Social cognition

ToM Task Battery-French version (Hutchins, Prelock, \& Chace, 2008; translated by Nader-Grosbois \& Houssa, 2016) 
The Theory of Mind Task Battery is composed of 15 test questions within 9 tasks (maximum 15 points). This measure consists of short vignettes presented in a story-book format designed to assess the ToM understanding of typical and atypical children (for instance, it is appropriate for nonverbal people). This test has been validated through test-retest reliability, internal consistency and external correlation.

Theory of Mind Inventory-French version (translated by Houssa, Mazzone, \& Nader-Grosbois, 2014; Hutchins, Prelock, \& Bonazinga, 2012)

This questionnaire is a measure of a caregiver's perception of children's ToM abilities. The ToMI has been developed for individuals aged 2 through 17 and is designed to determine a caregiver's impression of the thoughts and feelings of the child. It consists of 39 statements (e.g., "My child understands that people can lie to purposely mislead others"). Caregivers indicate their degree of agreement with each statement concerning their child by placing the appropriate vertical mark along a continuum ranging from "definitely not" to "definitely." The score for each item ranges from 0 to 20. The validation of the French version matched the original version. Cronbach's alpha was .94, and the coefficient of test-retest stability was very significant $(r=.86)$ (Houssa et al., 2014).

Social problem-solving task (RES, Barisnikov, Van der Linden, \& Hippolyte, 2004).

This task is used to assess children's capacity to judge whether or not other people's social behavior is appropriate, and makes it possible to determine the extent to which their judgment is based on a knowledge of conventional and/or moral rules. The task involves showing subjects 14 items illustrated by 14 pictures, consisting of five appropriate versus nine inappropriate social behaviors displayed by a character in social situations taken from everyday life. Three questions are asked. Firstly, the child has to say whether the social behavior is appropriate (good) or inappropriate (not good), and the maximum score is 28 points. The second question assesses the identification of the target behavior in the situation. The child has to show what is good or not good in the picture, and the maximum score is 14. Finally, the third question estimates the level of justification, in reference to social rules, associated with the judgment. The child has to justify why the behavior is good or not good (maximum score $=7$ ). Three response levels are proposed for this question, scoring 2, 5, or 7 points. The descriptive level corresponds to a justification in which the child merely describes the presented facts. For instance, the child might say "She is pulling the girl's hair". The intersubjective level corresponds to an explanation which reflects some social consciousness, but limited to an understanding of concrete aspects of the situation. For instance, the child might say "She is pulling the girl's hair and it hurts". The conceptual level reflects the link with social consciousness, with generalization. For example, the child might say "It isn't good to hurt somebody else". No point is given if a justification is not given, is inappropriate or reflects a misunderstanding of the situation. The maximum score for this 
question is 98 and for the three questions it is 140 . The validation was carried out with typically developing children and children with an intellectual disability. The inter-judge agreement was $98 \%$ congruent (Hippolyte, Iglesias, Van der Linden, \& Barisnikov, 2010).

A link could be established between the RES and the steps of the SIP model. When a child is presented with the situation in this tool, he or she is required to encode some social cues 1) and interpret them 2) in order to answer the questions. To be able to judge if the behavior is appropriate or not, and to be able to identify the target behavior, the child has to be able to interpret the social cues.

We were also able to link the RES with HAB. The RES is not a direct measure of $\mathrm{HAB}$, but the first question potentially throws light on HAB. For instance, if a child tends to say that the protagonist's behavior in the situations is inappropriate when it is appropriate, this could indicate a problem with the attribution of the protagonist's intentions.

Social adjustment

Social adjustment scales (EASE, Hughes, Soares-Boucaud, Hochman, \& Frith, 1998).

The EASE is a measure of an adult's perception of the socio-emotional adjustment skills of children. This tool was inspired by conceptions of ToM in social development. It includes items relating to social skills (non-ToM), but also items dealing with children's mentalization capacities and perspective-taking abilities (ToM). It can be completed by caregivers and/or teachers. For each item, caregivers/teachers have to indicate if the behavior is usual for the child $(0=$ non-existent or rare behavior, $1=$ frequent behavior, $2=$ usual behavior). The validation of this questionnaire was carried out on 327 typically developing children. The two subscales had good internal consistency; Cronbach's alpha was .77 for the "ToM subscale", and .79 for the "non-ToM subscale". The authors of the validation study found a significant regression between the "ToM subscale" and verbal developmental age $(r=.22)$ (Comte-Gervais, Giron, Soares-Boucaud, \& Poussin, 2008).

\subsection{Procedure}

Four different tests were initially administered to each participant across two sessions (lasting 25 to 40 minutes, according to the participant's attention span and availability). The tests were a measure of $\mathrm{HAB}$, a measure of developmental quotient and two measures of social cognition. Total administration time was 60 minutes. Children were tested individually in a quiet room. All participants were tested at school or at the Institute of Research in Psychological Sciences. Information letters and a consent form for the child's participation had previously been given to parents. Parents completed three questionnaires (EASE (Hughes et al., 1998), ToMI (Hutchins et al., 2012), and CBCL (Achenbach \& Rescorla, 2000)) and teachers completed two questionnaires (EBMCF (Roskam et al., 2000) and EASE). 


\subsection{Results}

Table 5 presents the results for the social cognition measures and the social adjustment score depending on the attribution type of the response (HAB group or non-HAB group). This table also shows the between-group comparisons. A first difference between the groups was found for extraversion: children in the HAB group were perceived by teachers as more extraverted than those in the non-HAB group. Moreover, parents scored the HAB group higher for EB than

Table 5. Mean scores (standard deviations) of all variables depending on attribution pattern and between-group comparisons for study 2 .

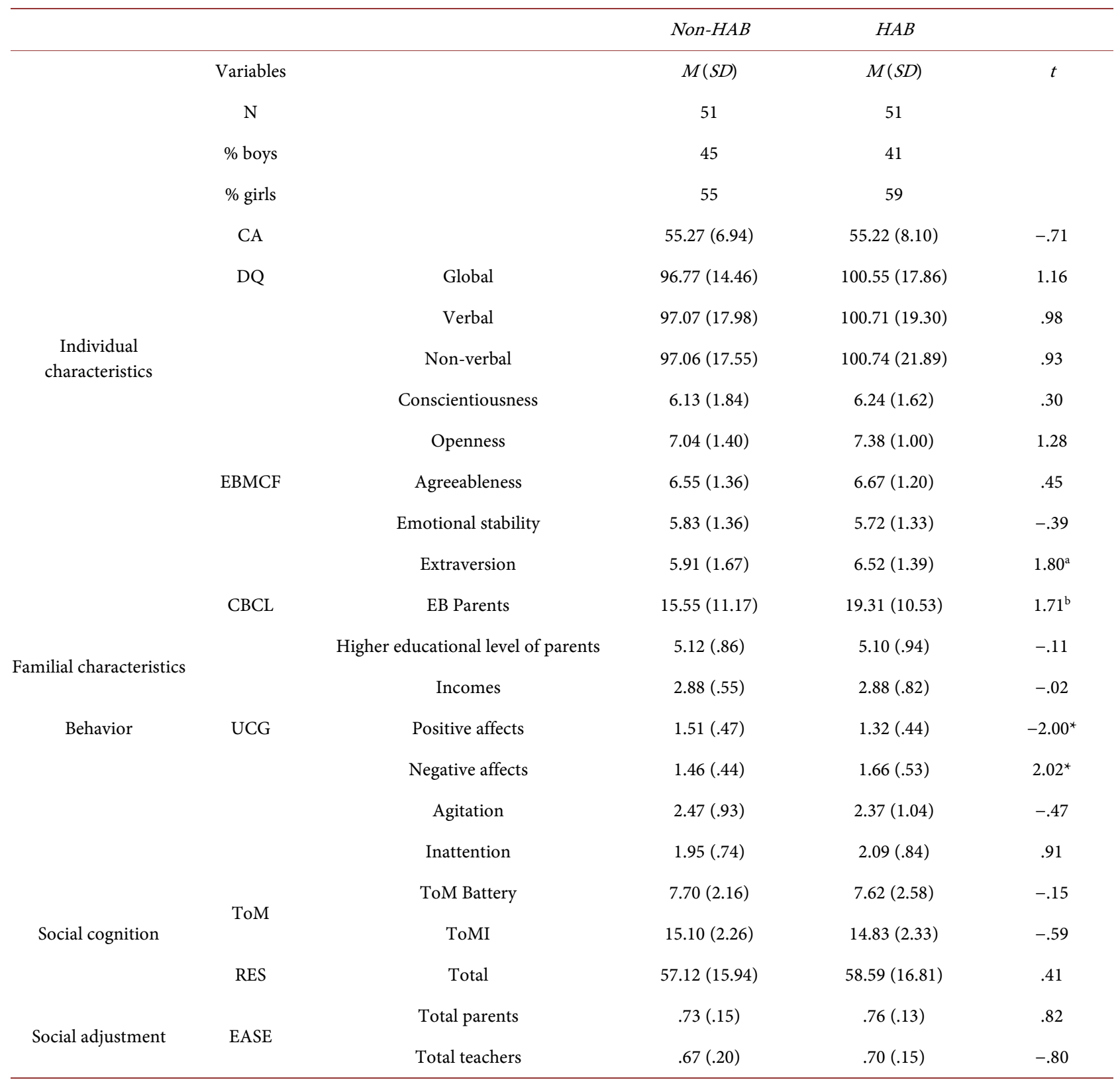

Notes. $\mathrm{HAB}=$ Hostile Attribution Bias; $\mathrm{CA}=$ Chronological Age; $\mathrm{DQ}=$ Developmental Quotient; $\mathrm{EBMCF}=$ Bipolar Rating Scales based on the Five Factor Model; $\mathrm{CBCL}=$ Child Behavior Checklist $\mathrm{EB}=$ Externalizing Behavior; ToM = Theory of Mind; ToMI = Theory of Mind Inventory; EASE = Social Adjustment Scales; RES $=$ Social problem-solving task. ${ }^{*} p<.05$; a $p=.07$; b $p=.09$. 
the non-HAB group. Finally, there were significant differences between groups concerning positive and negative affects in situations of frustration (i.e. in the UCG). Children in the non-HAB group expressed more positive affects and less negative affects than children in the HAB group. Contrary to what we expected, there was no difference between the groups for agitation or inattention. For all other variables, there was no difference between the groups.

\section{Discussion}

$\mathrm{HAB}$ is commonly identified in school-age children and is associated in particular with a high level of aggressive interactions with peers (Crick \& Dodge, 1994). According to several authors (Choe et al., 2013), preschool age may be an important period in which to work with children who exhibit HAB. This is because it is known that children who tend to make attributions of hostile intentions are at greater risk of being rejected by others and of displaying social maladjustment, and have limited opportunities to learn prosocial behaviors (Crick \& Dodge, 1994; Orobio de Castro et al., 2002).

Through these studies, we wanted to know if it is possible to detect the emergence of $\mathrm{HAB}$ in young children in a situation of frustration/provocation including a high level of personal involvement. Secondly, we tried to detect potential differences based on personality factors, social cognition, social adjustment and EB in order to identify the profiles of at-risk children. To be able to detect such profiles, it is necessary to have precise assessments of HAB for preschool age beyond developmental assessments of social cognition, ToM or social problem-solving.

Over the past decade, a number of authors have developed measures to evaluate $\mathrm{HAB}$ in young children. As there are no established norms to compare our results with, we can discuss them in relation to those with a proximal method or design. However, it is important to note that there are major differences from many other studies of HAB in the constitution of the sample. First, we included boys and girls, and not just boys. Secondly, we did not confine the sample to referred children, so that the mean level of aggressive behaviors was lower in our sample than in studies that enrolled children with identified aggressive behaviors. This was because we wished to include children with sufficiently variable EB levels to provide enough range to investigate data.

With regard to social cognition measures, we did not obtain the same results as Choe et al. (2013). Their study demonstrated that preschoolers with a higher understanding of emotions and beliefs exhibited less HAB during their school years. In our study, we did not observe any difference between our two matched groups ( $\mathrm{HAB} /$ non-HAB) in social cognition, including ToM measures.

The first reason for this could be that the measures used were not the same. In the study of Choe et al. (2013), children were asked to respond to hypothetical scenarios, while in the present study, the level of personal involvement was higher because we induced real-life frustration and children experienced the sit- 
uation directly. Secondly, we did not have the same number of situations to evaluate HAB. Choe et al. (2013) presented four hypothetical situations to children whereas we only used one. As Orobio de Castro et al. (2002) explained in their meta-analysis, the number of situations used to evaluate HAB was only (negatively) linked to effect size in non-referred extreme samples (for which larger effects were found when fewer situations were presented).

Thirdly, Choe et al. (2013) included an intelligence measure to examine a potential influence, but in our studies children were matched (in particular) on DQ. The lack of difference between our groups in study 2 could be explained by what Orobio de Castro et al. (2002) showed in their meta-analysis. After controlling for intelligence, the latter reported smaller effect sizes for other variables. We controlled for DQ in our studies to be sure that the results and relations between variables were not confused by individual differences in DQ. Furthermore, Orobio de Castro et al. (2002) explained that sociometric status also had an impact on effect sizes, whereas we observed no difference between groups in sociometric status. Finally, the objective of the two studies was not the same: that of the Choe et al. (2013) study was to predict HAB in school-age children on the basis of preschool characteristics whereas our study is transversal.

Concerning children's behavior, our results revealed a significant difference between groups in positive and negative affects during the UCG. Children who displayed HAB manifested less positive affects and more negative affects during the frustration task, especially when the virtual partner lost and allowed the child to receive only one candy (losing phase) when the child him- or herself had won and given five candies to the virtual partner (winning phase). This result confirms what Crick and Dodge (1994) showed: HAB can inhibit the development of positive social efficacy, even if social success is experienced (in this task, the children succeeded because they won all five rounds (winning phase). We did not find any differences between the groups with regard to agitation or inattention. This result could be interesting because it could suggest that the link between expression of affects and $\mathrm{HAB}$ differs from that between agitation and inattention and $\mathrm{HAB}$.

Furthermore, we reported some marginal differences between the groups. Compared with children who displayed no $\mathrm{HAB}$, children who did do so were perceived by teachers as more extraverted and by parents as having a higher level of EB. The current findings concerning extraversion confirm the previous results of Roskam, Meunier, Stievenart, and Van de Moortele (2009), who concluded that children assessed as highly extraverted developed less positively in behavioral adjustment. In terms of levels of $\mathrm{EB}$, our results confirmed studies of $\mathrm{HAB}$ showing that aggressive behavior is significantly associated with HAB. In their meta-analysis, (see Orobio de Castro et al., 2002 for a meta-analysis) noted that effect sizes differed between studies, notably because of the level of aggressive behavior. In our study, as already explained, not all the children had a pathological level of EB. The mean of our sample was below the pathological threshold of the CBCL, meaning that on average, the children did not have EB problems. 
Despite this, the UCG and questions assessing the HAB seemed effective at detecting preschoolers who were at risk of $\mathrm{HAB}$.

\section{Conclusions}

Through a measure with a high level of personal involvement, we were able to detect the proportion of preschoolers who displayed $\mathrm{HAB}$, even when they did not have a pathological level of EB. This measure meets some of the requirements stressed in the meta-analysis of Orobio de Castro et al. (2002), such as the importance of personal involvement in the task, and seems a promising method of evaluating $\mathrm{HAB}$ in young children.

Moreover, thanks to this measure, it is possible to identify children who made $\mathrm{HAB}$. After controlling for gender, age and $\mathrm{DQ}$, children who are perceived as more extraverted and having a higher level of EB are at risk of HAB. Faced with a situation of frustration/provocation, children with HAB are more likely to express less positive affects and more negative affects. Such reactions could be responsible for their rejection by peers. A child who systematically responds negatively limits his or her chances to learn prosocial behaviors; conversely, the expression of more positive affects and less negative affects could be a protective factor against the development of $\mathrm{HAB}$, whereas social cognitive competences seem to have no influence on the risk of HAB.

Future work could extend our findings by comparing this frustration/provocation situation with others with the same level of personal involvement or by increasing the sample and therefore providing significant results where we found only tendencies.

Finally, with regard to clinical implications, this measure could be used to evaluate $\mathrm{HAB}$ in young children, but also to give pointers regarding the need for intervention with at-risk children in order to teach them to interpret social cues properly when they experience an ambiguous or provocative situation. Dodge (2006) reported that change in attributional biases was difficult to achieve, because the children in the studies he described had developed HAB across many years. However, intervention with preschoolers might be more promising. Several authors have mentioned interventions relating to $\mathrm{HAB}$, but have failed to identify the variable that specifically impedes $\mathrm{HAB}$, because several variables have usually been manipulated together. Future research could test the effectiveness of an intervention focused specifically on HAB with preschoolers who are at risk.

\section{Acknowledgements}

We thank Prof. Marie-Pascale Noël for their advices in data analysis.

\section{References}

Achenbach, T. M., \& Rescorla, L. A. (2000). Manual for the ASEBA Preschool Forms \& Profiles. Burlington, VT: University of Vermont, Research Center for Children, Youth, 
\& Families.

Astington, J. W., \& Baird, J. A. (2005). Why Language Matters for Theory of Mind. New-York: Oxford University Press. https://doi.org/10.1093/acprof:oso/9780195159912.001.0001

Barisnikov, K., Van der Linden, M., \& Hippolyte, L. (2004). Tâche de résolution sociale. Manuel inédit. Genève.

Carlson, S. M., \& Moses, L. J. (2001). Individual Differences in Inhibitory Control and Children's Theory of Mind. Child Development, 74, 1032-1053. https://doi.org/10.1111/1467-8624.00333

Choe, D. E., Lane, J. D., Grabell, A. S., \& Olson, S. L. (2013). Developmental Precursors of Young School-Age Children's Hostile Attribution Bias. Developmental Psychology, 49, 2245-2256. https://doi.org/10.1037/a0032293

Comte-Gervais, I., Giron, A., Soares-Boucaud, I., \& Poussin, G. (2008). Evaluation de l'intelligence sociale chez l'enfant. L'information Psychiatrique, 84, 667-673. https://doi.org/10.3917/inpsy.8407.0667

Crick, N. R., \& Dodge, K. A. (1994). A Review and Reformulation of Social Information-Processing Mechanisms in Children's Social Adjustment. Psychological Bulletin, 115, 74-101. https://doi.org/10.1037/0033-2909.115.1.74

Dodge, K. A. (2006). Translational Science in Action: Hostile Attributional Style and the Development of Aggressive Behavior Problems. Development and Psychopathology, 18, 791-814. https://doi.org/10.1017/S0954579406060391

Dodge, K. A., \& Coie, J. D. (1987). Social Information Processing Factors in Reactive and Proactive Aggression in Children's Peer Groups. Journal of Personality and Social Psychology, 53, 1146-1158. https://doi.org/10.1037/0022-3514.53.6.1146

Dodge, K. A., \& Frame, C. L. (1982). Social Cognitive Biases and Deficits in Aggressive Boys. Child Development, 53, 620-635. https://doi.org/10.2307/1129373

Hippolyte, L., Iglesias, K., Van der Linden, M., \& Barisnikov, K. (2010). Social Reasoning Skills in Adults with Down Syndrome: The Role of Language, Executive Functions and Socio-Emotional Behaviour. Journal of Intellectual Disability Research, 54, 714-726. https://doi.org/10.1111/j.1365-2788.2010.01299.x

Houssa, M., Mazzone, S., \& Nader-Grosbois, N. (2014). Validation d'une version francophone de l'Inventaire de la Théorie de l'Esprit. Revue européenne de psychologie appliquée, 64, 169-179. https://doi.org/10.1016/j.erap.2014.02.002

Hughes, C., Oksanen, H., Taylor, A., Jackson, J., Murray, L., Caspi, A., \& Moffitt, T. E. (2002). "I’m Gonna Beat You!" SNAP!: An Observational Paradigm for Assessing Young Children's Disruptive Behaviour in Competitive Play. Journal of Child Psychology and Psychiatry and Allied Disciplines, 43, 507-516. https://doi.org/10.1111/1469-7610.00041

Hughes, C., Soares-Boucaud, I., Hochman, J., \& Frith, U. (1998). Comportement Social chez les enfants porteurs de troubles envahissants du développement: Effets du groupe, de l'informateur et de la "Théorie de l'esprit". Approche Neuropsychologique de l'Apprentissage de l'Enfant, 48, 78-85.

Hutchins, T. L., Prelock, P. A., \& Bonazinga, L. A. (2012). Psychometric Evaluation of the Theory of Mind Inventory (ToMI): A Study of Typically Developing Children and Children with Autism Spectrum Disorder. Journal of Autism and Developmental Disorders, 42, 327-341. https://doi.org/10.1007/s10803-011-1244-7

Hutchins, T. L., Prelock, P. A., \& Chace, W. (2008). Test-Retest Reliability of a Theory of Mind Task Battery for Children with Autism Spectrum Disorders. Focus on Autism 
and Other Developmental Disabilities, 23, 195-206.

https://doi.org/10.1177/1088357608322998

Nader-Grosbois, N., \& Houssa, M. (2016). Validation de la version francophone de la Batterie de tâches de la Théorie de l'esprit. Enfance, 2.

Orobio de Castro, B., Veerman, J. W., Koops, W., Bosch, J. D., \& Monshouwer, H. J. (2002). Hostile Attribution of Intent and Aggressive Behavior: A Meta-Analysis. Child Development, 73, 916-934. https://doi.org/10.1111/1467-8624.00447

Perron-Borelli, M. (1996). Echelles Différentielles d'Efficiences Intellectuelles. Forme révisée (EDEI-R). Paris: Editions et Applications Psychologiques.

Pettit, G. S., Dodge, K. A., \& Brown, M. M. (1988). Early Family Experience, Social Problem Solving Patterns, and Children's Social Competence. Child Development, 59, 107-120. https://doi.org/10.2307/1130393

Roskam, I., De Maere-Gaudissart, A., \& Vandenplas-Holper, C. (2000). Mise au point d'un instrument d'évaluation de la personnalité des enfants à partir du Modèle à Cinq Facteurs. L'orientation scolaire et professionnelle, 29, 661-672.

Roskam, I., Meunier, J. C., Stievenart, M., \& Van de Moortele, G. (2009). Troubles externalisés du comportement et facteurs de résilience chez l'enfant. Resilience, Regulation and Quality of Life: Concepts, Assessment and Intervention, 45.

Roskam, I., Stievenart, M., Brassart, E., Houssa, M., Loop, L., Mouton, B., Schelstraete, M.-A. et al. (2016). The Unfair Card Game: A Promising Tool to Assess Externalizing Behavior in Preschoolers. Pratiques Psychologiques, 22, 61-73.

https://doi.org/10.1016/j.prps.2015.09.004

Runions, K. C., \& Keating, D. P. (2007). Young Children's Social Information Processing: Family Antecedents and Behavioral Correlates. Developmental Psychology, 43, 838-849. https://doi.org/10.1037/0012-1649.43.4.838

Schultz, D., Ambike, A., Logie, S. K., Bohner, K. E., Stapleton, L. M., VanderWalde, H., Betkowski, J. A. et al. (2010). Assessment of Social Information Processing in Early Childhood: Development and Initial Validation of the Schultz Test of Emotion Processing-Preliminary Version. Journal of Abnormal Child Psychology, 38, 601-613. https://doi.org/10.1007/s10802-010-9390-5

Van Nieuwenhuijzen, M., Vriens, A., Scheepmaker, M., Smit, M., \& Porton, E. (2011). The Development of a Diagnostic Instrument to Measure Social Information Processing in Children with Mild to Borderline Intellectual Disabilities. Research in Developmental Disabilities, 32, 358-370. https://doi.org/10.1016/j.ridd.2010.10.012

Weschler, D. (2004). WPPSI-III: Manuel d'interprétation. Paris: Les Editions du Centre de Psychologie Appliquée.

Ziv, Y., \& Sorongon, A. (2011). Social Information Processing in Preschool Children: Relations to Sociodemographic Risk and Problem Behavior. Journal of Experimental Child Psychology, 109, 412-429. https://doi.org/10.1016/j.jecp.2011.02.009 